\title{
THE FATE OF PEOPLE WITH UNEXPLAINED GASTRIC ANACIDITY
}

\author{
Follow-up Studies \\ By A. L. BLOOMFIELD AND W. S. POLLAND \\ (From the Department bf Medicine, Stanford University Medical School, San Francisco).
}

(Received for publication January 28, 1935)

Until recent years it was generally believed that gastric anacidity indicated disease of clinical importance even though the patient at the moment presented no serious symptoms (1). Recently, however, as a result of extensive studies on more or less normal people it has become apparent that failure of the stomach to secrete acid, or for that matter any juice at all, even after so powerful a stimulus as histamine, is compatible with good health. Under the caption of "unexplained anacidity" we described several years ago a group of patients without gastrointestinal symptoms and without cancer of the stomach or pernicious anemia in whom anacidity after histamine was demonstrated as an accidental finding during the course of routine hospital studies (2). It seemed of importance to follow the subsequent course of these people with regard to their general state of health, and particularly to see whether they developed cancer of the stomach, pernicious anemia, or hypochromic anemia, conditions of which gastric anacidity has been claimed to be a precursor (3).

\section{MATERIAL}

The subjects were of the same type as those described in the previous paper (2), the general run of hospital patients. We excluded at the start (a) those in whom there was any suspicion of pernicious anemia, (b) those who had a hypochromic anemia with hemoglobin below 80 (Sahli), (c) those with gastro-intestinal symptoms more outspoken than the minor complaints of gas or occasional epigastric fullness, so common in any group of clinic patients, and (d) those with cancer of the stomach.

The presence of anacidity was established by the histamine test (4), and gastro-intestinal roentgenography was carefully done, aside from the usual general examination. Forty-three cases were followed for periods of from one to seven years in the anacidity clinic. Physical examinations, blood studies, and gastro-intestinal $\mathrm{x}$-rays were made from time to time and the histamine test was repeated in many instances. Only one patient was lost track of during the period of study. Another died of a stroke. There were twenty-two females and twenty-one males. Only six of the whole group were under 40 years of age; most of them were in the period when pernicious anemia and cancer are common.

\section{Development of cancer of the stomach in people with gastric anacidity}

The duration of the follow-up with reference to development of cancer of the stomach was as follows:

Years followed .......12 1234556789101112

Number of patients ... 341216241 1* $1 \dagger$

* Anacidity to Ewald Meal in 1924; first histamine test in 1929.

$\dagger$ Anacidity to Ewald Meal in 1922; first histamine test in 1930.

In no case did cancer of the stomach develop. In most instances gastro-intestinal $x$-rays were repeated toward the end of the follow-up period, in nearly all, the patient was seen and examined, in a few, a report which seemed conclusive came by letter.

\section{Development of pernicious anemia in people with gastric anacidity}

The duration of the follow-up with reference to development of pernicious anemia was as follows :

Years followed .........12 1234456789101112 Number of patients ..... 333121524111

In nearly every case the patient was carefully examined at the end of the follow-up period for physical evidences of pernicious anemia (tongue, spleen, cord changes) and blood studies were made. In a few instances the patient could not return but wrote about his condition in reply to a questionnaire. In none of the group was there 
any suggestion that pernicious anemia had developed.

During the course of the study, however, there came to our attention two patients who deserve a word of comment. Neither is included in the series reported above.

E. S. (No. 194344), a salesman, 48 years old, came to the clinic in November 1929 for mild epileptiform attacks. There were no symptoms or physical signs to raise any suspicion of pernicious anemia. There were no gastro-intestinal symptoms but the histamine test showed an anacidity with practically no gastric secretion. Blood: (November 1929) R.B.C. 5.4 M, Hb. 17.2 grams per cent, W.B.C. 9200, no morphological abnormalities. April 1931. Patient perfectly well. Blood: R.B.C. 4.98 M, Hb. 16.6 grams per cent, C.I. 0.99, W.B.C. 9200 . Platelets 313,000. Price-Jones curve normal. June 1932. Patient well. Second histamine test, complete anacidity. Blood: R.B.C. $5.2 \mathrm{M}, \mathrm{Hb} .17 .5$ grams per cent, C.I. 0.97, W.B.C. 9400. Platelets 387,000 . There was a definite tendency to macrocytosis. The Price-Jones curve was shifted to the right and there were a good many cells with diameters between 9 and $10 \mu$.

The question arose as to whether one was dealing with the earliest evidences of pernicious anemia, but in 1934 the patient who had had no liver therapy was perfectly well.

The second case was that of J.A., a man of 45 years who came to the clinic in January 1930 with the complaint of diarrhea off and on for six years. Physical examination was not remarkable aside from acne rosacea and slight undernutrition. Gastro-intestinal $\mathbf{x}$-ray studies were normal. Barium enema, normal. Histamine test showed complete anacidity. Blood: R.B.C. $4.7 \mathrm{M}, \mathrm{Hb}$. 14.3 grams per cent, W.B.C. 8,900. No morphological changes. The diarrhea stopped after administration of dilute hydrochloric acid; the man gained twenty-five pounds and has remained well. April 1931. Blood: R.B.C. $4.6 \mathrm{M}$, Hb. 15.5 grams per cent, C.I. 0.98, W.B.C. 8800. Morphology normal. Price-Jones curve, normal. April 1932. Blood: R.B.C. $4.6 \mathrm{M}, \mathrm{Hb} .15 .7$ grams per cent, C.I. 0.99, W.B.C. 8600 . There was marked anisocytosis with many macrocytes, the Price-Jones curve being markedly shifted to the right. August 1932. Blood: R.B.C. $4.7 \mathrm{M}, \mathrm{Hb} .16 .9$ grams per cent, C.I. 1.04, W.B.C. 7800 . The cells showed marked anisocytosis and slight polychromasia. The average red cell diameter was $8.07 \mu$. There were many large cells.

Here again the suspicion of early pernicious anemia was aroused, but since the patient is perfectly well two years later no conclusion can be reached.

\section{The development of hypochromic anemia in patients with anacidity}

During the course of this study we encountered six cases of hypochromic anemia with anacidity.
They presented the usual features of the syndrome with prompt improvement of the blood on iron therapy, and relapse when iron was discontinued for any length of time. These patients were excluded at the start from the group of "unexplained anacidities" with which we are dealing in the present report. Of the patients with anacidity who were not anemic at the start of the follow-up period none developed hypochromic anemia. One patient on one occasion had only 11.2 grams of hemoglobin per cent but subsequently his blood was normal without administration of iron. This fact, that none of the patients became anemic, seems of considerable interest since it suggests that some influence other than anacidity is of major importance in precipitating the blood changes. We have discussed this matter in detail elsewhere (5).

\section{Permanence of anacidity}

In our experience anacidity following an injection of histamine is almost always permanent; restoration of anything approaching a normal gastric secretion is out of the question (6). In the present series the histamine test was repeated one or more times after varying intervals (one to four years) in 25 cases. Anacidity persisted in all but one. This was a man of 60 years who secreted no acid in June 1931 but in March 1934 he attained a free acid of 31 and total acid of 44 . Whether there was an actual restoration of slight secretory ability or whether a small amount of acid was obscured by mucus on the first test can not be said definitely.

\section{General course of events in patients with unexplained anacidity}

As we followed these patients year after year nothing of note developed in regard to their general condition; certainly one did not get the impression that anacidity led to the development of any clinical symptoms, or that it shortened life. Patient $E d$, for example, who was 67 years old at the start of the study has been followed for 4 years with no deterioration of health. Patient $K o$, first seen six years ago, had a cholecystectomy and has been well ever since. Patient $E l, 75$ years old at the start of the follow-up period, with arteriosclerosis and myocarditis, remains about the same four years later. 


\section{DISCUSSION}

Forty-three clinic patients, for the most part with minor disabilities, in whom gastric anacidity was discovered as an accidental finding were carefully followed over periods varying up to seven years. In no case was there evidence that the absence of gastric secretion led to the development of any particular symptoms or to general impairment of health; in no case did cancer, hypochromic anemia or pernicious anemia supervene. The anacidity persisted except in one instance in which after an interval small amounts of acid were demonstrated.

While these observations in no way contradict the general view that gastric anacidity may be a precursor of cancer of the stomach or of pernicious anemia, they indicate that the hazard to the individual is very small. Statistics also make this clear. Thus the death rate from pernicious anemia from 1921 to 1929 is reported as about 8.6 per 100,000 (7), and if one assumes that before the introduction of liver therapy the average duration of life was five years, then one might conclude that the incidence in the population at large was 43 per 100,000. But among 100,000 people in the pernicious anemia age period there are at least 15,000 with anacidity (8). Hence the chance on a statistical basis alone of any individual with anacidity developing pernicious anemia is only about 3 per 1000 , or roughly one in three or four hundred.

The fact that none of these individuals with deficient gastric secretion developed pernicious anemia requires a further word of comment in view of the current theories of pathogenesis of this disease. The view seems generally accepted in this country, following the work of Castle, that the anemia results from the absence of a substance normally formed by interaction of a constituent of the gastric juice (intrinsic factor) with ingested protein (beef). The intrinsic factor according to Castle is independent both of acid and of pepsin and the question comes up whether it is present in the stomachs of these patients with anacidity who do not develop pernicious anemia. The data on this point are in conflict. Castle reported two such patients in whose gastric juice he was able to demonstrate the intrinsic factor in spite of anacidity (9). Barnett in our clinic, on the other hand, was unable to secure it from the secretions of several pedigreed cases of simple anacidity without anemia (10). A priori, it seems improbable, if not impossible, that most of the patients with unexplained anacidity can secrete the " intrinsic factor"- -at least in quantity enough to serve any practical purpose. It should be recalled that most of these people not only secrete no acid but really produce no gastric juice at all (11). Even after histamine there is no response, and aspiration over a period of an hour yields only a few cubic centimeters of mucoid material. Extraction of gastric contents after a meal of beef shows that the food is not digested and even if traces of "intrinsic factor" should be present it is difficult to see how they could mechanically come in contact with the ingesta in such a way as to liberate the anti-anemic substance. Be this as it may, the two patients with unexplained anacidity in whom Barnett was unable to demonstrate the "intrinsic factor" in 1931 have been followed up to the present time without showing any signs of pernicious anemia. The crucial experiment of course would be an assay for anti-anemic substance of the livers of achylia patients without anemia, and this we hope to do when material is available.

All this to our minds indicates that the absence of Castle's intrinsic factor in the gastric juice does not necessarily lead to the development of pernicious anemia. Apparently only an occasional person needs the protection of the Castle-Minot anti-anemic substance to safeguard himself against the disease whatever the ultimate cause of it may turn out to be. This view is supported by reports of blood changes after gastrectomy resembling those of pernicious anemia (12). The rare cases in which this occurs only serve to emphasize the vastly greater number of gastrectomies following which pernicious anemia does not develop. So too, very occasionally, when the gastric mucosa is seriously altered in connection with cancer of the stomach, does pernicious anemia develop (13), but in the vast majority of cases anemia is not of the Addisonian type.

\section{CONCLUSIONS}

Forty-five patients with unexplained anacidity as previously defined were followed over periods of from one to seven years. In no case did 
cancer of the stomach, hypochromic anemia, or pernicious anemia supervene. The implications of these findings especially with reference to the etiology of pernicious anemia are discussed.

\section{BIBLIOGRAPHY}

1. Bloomfield, A. L., and Polland, W. S., Gastric Anacidity. Its Relation to Disease. Macmillan Co., New York, 1933, p. 79 et seq.

2. Polland, W. S., and Bloomfield, A. L., Unexplained gastric anacidity. Arch. Int. Med., 1931, 48, 412.

3. Hurst, A. F., The precursors of carcinoma of the stomach. Lancet, 1929, 2, 1023.

Achlorhydria and achylia gastrica, and their connection with Addison's anemia. Quart. J. Med., 1932, $1,157$.

4. See reference (1), p. 11.

5. Bloomfield, A. L., Relations between primary hypo- chromic anemia and chlorosis. Arch. Int. Med., 1932, 50, 328.

6. See reference (1), p. 47.

7. Statistical Bulletin, Metropolitan Life Insurance Co. 1930, 11, 2.

8. See reference (1), p. 55 .

9. Castle, W. B., Heath, C. W., and Strauss, M. B., Observations on the etiologic relationship of achylia gastrica to pernicious anemia. IV. Am. J. M. Sc., 1931, 182, 741.

10. Barnett, C. W., The significance of the gastric secretions in pernicious anemia. Am. J. M. Sc., 1932, 184, 24.

11. See reference (1), p. 34 .

12. Goldhamer, S. M., The pernicious anemia syndrome in gastrectomized patients. Surg. Gynec. and Obst., 1933, 57, 257.

13. Conner, H. M., and Birkeland, I. W., Coexistence of pernicious anemia and lesions of the gastro-intestinal tract. I. Carcinoma of the stomach. Ann. Int. Med., 1933, 7, 89. 